\title{
ENTOMOFAUNA EN LAS PRINCIPALES MALEZAS ASOCIADAS A LOS CULTIVOS DE MAÍZ, CÍTRICOS Y LÚCUMO Y SU POBLACIÓN ESTIMADA POR HECTÁREA EN LA MOLINA, LIMA. PERÚ
}

\author{
ENTOMOFAUNA IN MAJOR WEEDS ASSOCIATED WITH MAIZE, CITRUS \\ AND LUCUMO AND ESTIMATED PER HECTARE IN LA MOLINA, LIMA'S POPULATION. \\ PERU
}

\author{
${ }^{1}$ Jorge Castillo V., ${ }^{2}$ Patricia Rodríguez Q., ${ }^{3}$ Pedro Molina S., ${ }^{3}$ Manuel Cardozo Z. y ${ }^{3}$ Cesar Vega R.
}

\begin{abstract}
Resumen
El estudio se realizó en el campus de la Universidad Nacional Agraria La Molina para obtener datos numéricos a través de muestreos sistemáticos de poblaciones de malezas en los cultivos de maíz, cítricos y lúcumo, la colección e identificación de insectos presentes en estas malezas y su proyección por hectárea. Entre las tres maleza más importantes evaluadas por cada cultivo, la "grama china" (Sorghum halepense L.) está presente en los tres cultivos evaluados. Las más abudantes en maíz son "chamico" (Datura stramonium L.) y "coquito" (Cyperus rotundus L.), para el cultivo de cítricos son el "yuyo" (Amaranthus spp.) y "leche leche" (Euphorbia spp); y para el cultivo de lúcumo "yuyo" y "amor seco" (Bidens pilosa L.). En el cultivo del maíz, se recuperaron 34 especies de insectos, con una proyección de 1100 000 individuos/ha, de los cuales el $55.84 \%$ son plagas de malezas y cultivos, $40.36 \%$ sin importancia económica y 3.79 \% son insectos parasitoides. La "grama china" registró el mayor número con una población de 725000 insectos/ha.

En los cítricos se registró 11 333, 35000 y 94500 insectos/ha en "grama china", "yuyo" y "leche leche", respectivamente. De estas malezas se recuperaron 52 especies de insectos, con una población estimada de 140833 individuos/ha, de los cuales el $46.44 \%$ no son de importancia económica, $22.96 \%$ son plagas de cultivos, $22.23 \%$ representan plagas de malezas y $9.24 \%$ son insectos predatores. En el cultivo de lúcumo, la maleza "amor seco" presentó una población estimada de 416000 insectos/ha, seguida por "yuyo" con una población estimada de 152292 insectos/ha. Se recuperaron 37 especímenes de insectos, con un estimado de 568958 individuos/ha, de los cuales el 54.92\% no son de importancia económica, $26.81 \%$ son plagas de malezas, $14.65 \%$ son plagas de cultivos y $3.66 \%$ son insectos benéficos.
\end{abstract}

Palabras clave: malezas, maíz, cítricos, lúcumo, insectos fitófagos.

\begin{abstract}
The study was conducted on the campus of the Universidad Nacional Agraria La Molina for numerical data through systematic sampling of populations of weeds in corn, citrus and lúcumo, collection and identification of insects on these weeds and their projection per hectare. Among the three major weeds evaluated for each crop, "china grass" (Sorghum halepense L.) is present in all three crops evaluated. The most abudantes corn are "fireweed" (Datura stramonium L.) and "Coquito" (Cyperus rotundus L.) for growing citrus are the "weed" (Amaranthus spp.) and "milk milk" (Euphorbia spp); and for growing lúcumo "weed" and "dry love" (Bidens pilosa L.). In the cultivation of maize, 34 insect species were recovered, with a projected 1.1 million individuals/ha, of which $55.84 \%$ are pests of crops and weeds, without economic importance $40.36 \%$ and $3.79 \%$ are parasitoids. The "china grass" recorded the highest number with a population of 725000 insects/ha. In citrus 11333,35000 and 94500 insects/ha was recorded in "china grass", "weed" and "milk milk", respectively. Of the 52 weed species of insects were recovered, with an estimated 140833 individuals/ ha population, of which $46.44 \%$ are not economically important, $22.96 \%$ are pests of crops, pests represent $22.23 \%$ and $9.24 \%$ of weeds are insect predators. In growing lucumo, weed "dry Love" provided an estimated 416000 insects / ha, followed by "weed" with an estimated 152,292 insects/ha population population. 37 insect specimens were recovered, with an estimated 568958 individuals/ha, of which $54.92 \%$ are not economically important, $26.81 \%$ are weed pests, $14.65 \%$ are crop pests and beneficial insects are $3.66 \%$.
\end{abstract}

Key words: weed, corn, citrus, lucumo, phytophagous insects.

\footnotetext{
${ }^{1}$ Universidad Nacional Agraria La Molina, Lima, Perú. E-mail:. joracava@lamolina.edu.pe ${ }^{2}$ Universidad Nacional Agraria La Molina, Lima, Perú. E-mail: srodriguez@lamolina.edu.pe

Ingeniero Agrónomo. SENASA.pmolina@senasa.gob.pe, mcardozo@senasa.gob.pe, cvega@senasa.gob.pe
} 


\section{Introducción}

La prevención y el control de plagas tienen como una de las medidas más recomendadas la eliminación de malezas ya que éstas son hospederas de insectos y patógenos que se convierten en plagas agrícolas. No todas las malezas han sido estudiadas en cuanto a su interacción con problemas fitosanitarios y solo se han reportado casos aislados y referenciales de su asociación con algunas plagas.

La presencia de malezas podría estár relacionada con un descuido en la preparación de terreno como inicio de una campaña agrícola, a esto se añade la práctica común de alquilar terrenos para sembrar, donde el agricultor no considera en el manejo fitosanitario el tiempo que transcurre entre la preparación de terreno y la instalación de un nuevo cultivo, especialmente en cultivos anuales y perennes, donde el desmalezado es considerado como una labor secundaria. Los problemas fitosanitarios pueden generarse al tener plantas hospederas de plagas de cultivos que elevan los costos de producción al recurrir al uso de herbicidas, insecticidas y/o fungicidas para resolver el problema.

Muchos entomólogos, fitopatólogos y malezólogos concuerdan en que la intensificación que ha acompañado al crecimiento de la agricultura ha promovido prácticas que favorecen las plagas de insectos, malezas y enfermedades (Altieri, 1997). Solo se enfocan las malezas como entes biológicos que compiten con los cultivos principales y que son fuentes de plagas y enfermedades (Cerna 1994, Cisneros, 1995 y Apablaza et al, 2003), sin embargo no se han hecho la cuantificación de los insectos plagas y los controladores biológicos y realizar el balance ecológico de la presencia de los insectos en general (Altieri, 1997).

Muchas veces las malezas son la única fuente de flores en el agroecosistema convirtiéndose en un recurso de gran importancia para que los adultos de los parásitos puedan sobrevivir durante períodos críticos cuando los hospedantes son escasos (Syme, 1975). Así, los parásitos tienen más oportunidades de establecerse en áreas donde puedan encontrar una rica vegetación de plantas productoras de néctar y polen, que en aquellas áreas ausentes de flores silvestres, hecho a considerar cuando se decide implantar programas de manejo integrado de plagas (Altieri, 1976, 1980, 1981).

Las áreas cercanas a los cultivo, que no son cultivadas, que se encuentran con diversa vegetación, son componentes importantes en la estabilidad del agroecositema, pudiendo ser el refugio de muchos controladores parasitoides y predatores (Menash y Sequeira, 2004). Estos refugios pueden alentar la sobrevivencia, fecundidad y el comportamiento de los insectos benéficos, incrementando la colonización de dichos controladores en los cultivos que se instalen y contribuir al control de las diferentes problemas fitosanitarios (Landis et al., 2000). Las malezas predominantes para los diferentes cultivos varían notoriamente si el cultivo es anual o si es un frutal, a pesar de que la localización de los campos evaluados no diste más de 200 metros entre sí. Las diferentes malezas por cada cultivo dependen de la preparación de terreno, prácticas culturales, niveles tróficos hasta el nivel de vertebrados, tal como lo explica Marshall et al (2003),

La importancia de conocer y cuantificar los insectos presentes al momento de decidir el mejor manejo agronómico tanto para pequeños y medianos agricultores así como para las empresas de agroexportación determina como objetivo del estudio, identificar, cuantificar $\mathrm{y}$ proyectar por hectárea las poblaciones de malezas e insectos que se encuentran asociados en los cultivos de maíz, cítricos y lúcumo, a través de muestreos sistemáticos de poblaciones de malezas en el campo.

\section{Materiales y métodos}

Para la fase de campo, se seleccionaron los cultivos de maíz, cítricos y lúcumo, anual y perennes, instalados en campos colindantes dentro del campus de la Universidad Nacional Agraria La Molina, por ser un modelo o dseño representativo de la colindancia entre campos de cultivo anuales y perennes entre los agricultores.

Como antecedentes en el campo de maíz, el manejo de malezas se inicia con la aplicación de un herbicida para el control de malezas de hoja ancha (atrazina) al inicio de campaña y para el desmalezado de hoja angosta se realiza en forma manual. Para el caso de los cítricos y el lúcumo, se realiza la aplicación de glifosato en tres oportunidades y no se realiza deshierbos manuales. Los períodos de evaluación fueron en noviembre del 2010 para el cultivo de maíz, que se encontraba en período de crecimiento vegetativo, en enero del 2011 para los cítricos que se encontraban en período de floración, y en febrero del 2011 para el lúcumo que se encontraba en período de fructificación. Los períodos fenológicos estudiados en cada cultivo corresponden a la presencia de malezas que aparecieron de acuerdo al manejo del riego por gravedad.

Para la evaluación de malezas en campo de los cultivos seleccionados primero se determinaron tres $(03)$ malezas predominantes (A, B y C), su distribución y abundancia en cada cultivo. Para ello, se delimitó al azar cinco (05) unidades de muestreo (5 repeticiones) de un área de $4 \mathrm{~m}^{2}$ cada una para cada cultivo, según el croquis del campo de la Fig. 1.

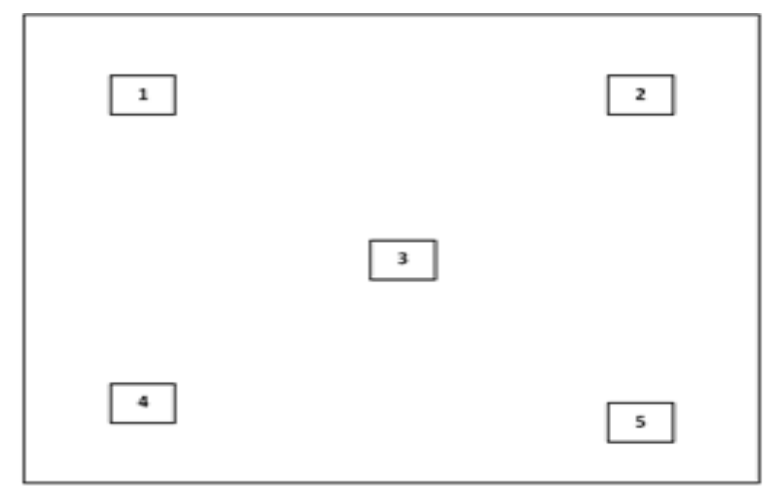

Figura 1. Croquis del campo con ubicación de 5 parcelas para la evaluación de malezas. 
El método de evaluación aplicado considera a la maleza como refugio u hospedero potencial de plagas, enfermedades y enemigos naturales. Luego de una observación general y el conteo de las malezas en el área, se registraron las predominantes y su número por unidad de muestreo y se transformaron a $1 \mathrm{~m}^{2}$.

Para cada cultivo se tomaron tres plantas o repeticiones de las tres malezas predominantes; especie de maleza A: 3 plantas; especie de maleza B: 3 plantas; especie de maleza C: 3 plantas. Lo que hace un total de 9 plantas por cada cultivo.

En total se colectaron 27 muestras para los tres cultivos. Se colectó todo el follaje y la raíz de la maleza, luego fueron colocadas en bolsas de plástico cerradas e identificadas.

En la fase de laboratorio, las 27 muestras de las malezas se acondicionaron en frascos de vidrio en un laboratorio del Museo de Entomología de la Universidad Nacional Agraria La Molina bajo condiciones ambientales naturales. En el fondo de cada frasco se colocó papel toalla y se tapó la boca con tul y una banda de goma elástica. Luego de un promedio de 20 días, se inicio el registro de los insectos recuperados y se individualizaron en placas de petri. Los insectos adultos emergidos se montaron en alfileres entomológicos para su identificación. Para la identificación de los especímenes se contó con el apoyo del Laboratorio de Entomología del Centro de Diagnóstico de Sanidad Vegetal del SENASA y del Museo de Entomología de la Universidad Nacional Agraria La Molina.

En la fase de gabinete, se procedió a realizar las proyecciones por hectárea de las diferentes especies colectadas en cada maleza para cada cultivo. Para el caso del presente estudio, no se evaluaron insectos en los cultivos, solamente se evaluó insectos en la flora acompañante de los mismos y a nivel de adultos. Esta proyección nos da una idea del potencial de poblaciones presentes que pueden ser una amenaza pocas veces considerada debido a que la práctica común de evaluación de los campos en producción está orientada a los cultivos más no a las malezas.

\section{Resultados y discusión}

Para los tres cultivos, se han identificado los insectos hasta género y en ciertos casos se ha identificado a nivel de familia. En todos los casos se ha proyectado la presencia de insectos ya sea por género, especie ó familia a número de individuos por hectárea.

\section{Cultivo de maíz}

De las evaluaciones realizadas en campo y gabinete para el cultivo de maíz se determinaron las siguientes poblaciones de malezas de la tabla 1 .
Tabla 1. Proyección estimada de población de malezas predominantes en el cultivo de maíz, por hectárea.

\begin{tabular}{ccc}
\hline Nombre científico & $\begin{array}{c}\text { Nombre } \\
\text { común }\end{array}$ & $\begin{array}{c}\text { Población } \\
\text { estimada } \\
\text { No plantas/ha }\end{array}$ \\
\hline Datura stramonium & "chamico" & 125,000 \\
Sorghum halepense & "grama & 87,000 \\
china" & 22,000 \\
\hline Cyperus rotundus & "coquito" & 234,000 \\
\hline
\end{tabular}

Para el caso de "chamico" se determinó un promedio de 12.5 plantas $/ \mathrm{m}^{2}$ siendo la especie de mayor distribución en el campo de maíz evaluado. En segundo lugar, "grama china" con un promedio de 8.7 plantas $/ \mathrm{m}^{2}$ lo que representa 87,000 plantas/ha. En tercer lugar, "coquito" con un promedio de 2.2 plantas $/ \mathrm{m}^{2}$ y 22,000 plantas/ha.

Tabla 2. Ordenes de insectos recuperados en cultivo de maíz por cada maleza.

\begin{tabular}{ccc}
\hline $\begin{array}{c}\text { Nombre científico de } \\
\text { la maleza }\end{array}$ & Orden & $\begin{array}{c}\text { Población estimada } \\
\text { de } \\
\text { insectos/ha }\end{array}$ \\
\hline Sorghum halepense & Hemiptera & 464,000 \\
& Diptera & 261,000 \\
Datura stramonium & Hemiptera & 291,666 \\
& Hymenoptera & 41,667 \\
& Diptera & 41,667 \\
Cyperus rotundus & -- & 0 \\
\hline Total & & $1 ' 100,000$ \\
\hline
\end{tabular}

Tabla 3. Familias de insectos recuperados por cada maleza en cultivo de maíz.

\begin{tabular}{ccc}
$\begin{array}{c}\text { Nombre científico de } \\
\text { la maleza }\end{array}$ & Familia & $\begin{array}{c}\text { Estimado por } \\
\text { ha }\end{array}$ \\
\hline \multirow{4}{*}{ Sorghum halepense } & Aphididae & 116,000 \\
& Aleyrodidae & 29,000 \\
& Rhopalidae & 319,000 \\
& Agromyzidae & 261,000 \\
\hline Sub-Total & Aphididae & 166,666 \\
& Rhopalidae & 125,000 \\
Datura stramonium & Pteromalidae & 41,667 \\
& Agromyzidae & 41,667 \\
\hline \multicolumn{3}{c}{ Sub-Total } \\
\hline Typerus rotundus \\
\hline
\end{tabular}


Tabla 4. Especies de insectos identificados en malezas del cultivo de maíz.

\begin{tabular}{ccc}
\hline $\begin{array}{c}\text { Nombre científico } \\
\text { de la maleza }\end{array}$ & Género y especie & $\begin{array}{c}\text { Estimado } \\
\text { por ha }\end{array}$ \\
\hline & Liorrhyssus $\mathrm{sp}$. & 319,000 \\
Sorghum halepense & Liriomyza $\mathrm{sp}$. & 261,000 \\
& Metopolophium $\mathrm{sp}$. & 116,000 \\
& Bemisia $\mathrm{sp}$. & 29,000 \\
Datura stramonium & Rhopalosiphum maidis & 166,666 \\
& Liorrhyssus $\mathrm{sp}$. & 125,000 \\
& Halticoptera $\mathrm{sp}$. & 41,667 \\
Liriomyza $\mathrm{sp}$. & 41,667 \\
\hline Cyperus sp. & -0 \\
\hline Total & & 1 '- 100,000 \\
\hline
\end{tabular}

Tabla 5. Status de insectos recuperados, población de insectos estimada por hectárea y porcentaje de insectos por maleza, en el cultivo de maíz.

\begin{tabular}{|c|c|c|c|}
\hline $\begin{array}{c}\text { Nombre científico de } \\
\text { la maleza }\end{array}$ & $\begin{array}{l}\text { Status del } \\
\text { insecto }\end{array}$ & $\begin{array}{c}\text { Estimado por } \\
\text { ha }\end{array}$ & $\begin{array}{l}\% \text { por } \\
\text { maleza }\end{array}$ \\
\hline \multirow[t]{2}{*}{ Sorghum halepense } & Plaga & 406,000 & 56 \\
\hline & $\begin{array}{l}\text { Sin Import. } \\
\text { Econ. }\end{array}$ & 319,000 & 44 \\
\hline Sub-Total & & 725,000 & 100 \\
\hline \multirow[t]{3}{*}{ Datura stramonium } & plaga & 208,333 & 56 \\
\hline & sin import. & 125,000 & 33 \\
\hline & parasitoide & 41,667 & 11 \\
\hline Sub-Total & & 375,000 & 100 \\
\hline Cyperus rotundus & -- & 0 & 0 \\
\hline Total & & & '100,000 \\
\hline
\end{tabular}

Tabla 6. Resumen del status de insectos recuperados y población estimada por hectárea en el cultivo de maíz.

\begin{tabular}{cccc}
\hline $\begin{array}{c}\text { Nombre del } \\
\text { cultivo }\end{array}$ & Status del insecto & $\begin{array}{c}\text { Estimado } \\
\text { por ha }\end{array}$ & \% por maleza \\
\hline \multirow{2}{*}{ Maíz } & plaga & 614,333 & 55.84 \\
& sin import. econ. & 444,000 & 40.36 \\
& parasitoide & 41,667 & 3.79 \\
\hline Total & & $1^{\prime} 100,000$ & 100 \\
\hline
\end{tabular}

De acuerdo a las tablas 2, 34 y 5 se puede observar que, en el cultivo de maíz la "grama china" alberga la mayor cantidad de insectos, seguida del "chamico" con la mitad de insectos, en cambio no se recuperó ningún insecto en "coquito".

En cuanto al número promedio de insectos recuperados por planta en cada maleza predominante y estimados por hectárea en el cultivo del maíz; en "grama china" se recuperaron en promedio 11 insectos por planta, lo que proyecta un población de 957,000 insectos/ha. De igual manera, en "chamico", se recuperaron en promedio 3 insectos por planta, con una población estimada de 375,000 insectos/ha.

La mayoría de insectos en ambas malezas pertenecen al orden Hemiptera, seguidos del orden Diptera y, en menor proporción se recuperaron insectos del orden Hymenoptera. En cuanto a las familias de los insectos recuperados en "grama china", las mayores poblaciones pertenecen a las familias Rhopalidae, Agromyzidae y Aphididae, y las menores poblaciones pertenecen a la familia Aleyrodidae. En "chamico" las mayores poblaciones pertenecen a las familias Aphididae y Rhopalidae y las menores poblaciones pertenecen a las familias Pteromalidae y Agromyzidae.

En cuanto a las especies recuperadas en "grama china"; las mayores poblaciones pertenecen a ninfas de Liorrhyssus sp., seguida de Liriomyza sp. (a nivel de puparios) y las menores poblaciones pertenecen a Liriomyza sp. (Adultos), Metopolophium sp. y a Bemisia sp. En "chamico" las mayores poblaciones recuperadas pertenecen a Rophalosiphum maydis y un género sin identificar de ninfas de Rhopalidae, Liorrhyssus sp. Las menores poblaciones pertenecen a Halticoptera sp. y Liriomyza sp. (Puparios), según el cuadro 4.

Tomando en cuenta el status de los insectos recuperados tenemos que en "grama china" un 56\% de insectos representan a plagas y un $44 \%$ representan insectos sin importancia económica. En "chamico" un $56 \%$ representan insectos sin importancia económica, 33 $\%$ representan a plagas y $11 \%$ representan a insectos benéficos, según la Tabla 5.

En total, en las malezas evaluadas en el cultivo de maíz, se recuperaron 34 especímenes de insectos (individuos), representando un estimado de población por hectárea de 1'100,000 individuos, de los cuales el 55.84 \% representan a plagas, $40.36 \%$ no son de importancia económica y $3.79 \%$ son insectos benéficos, según la Tabla 6 .

\section{Cultivo de cítricos}

De las evaluaciones realizadas en campo y gabinete para el cultivo de cítricos se determinaron las siguientes poblaciones de malezas de la Tabla 7.

Tabla 7. Proyección estimada de población de malezas predominantes en el cultivo de cítricos, por hectárea.

\begin{tabular}{ccc}
\hline Nombre científico & Nombre común & $\begin{array}{c}\text { Población } \\
\text { estimada } \\
\text { No plantas/ha }\end{array}$ \\
\hline Sorghum halepense & "grama china" & 34,000 \\
Amaranthus sp. & "yuyo" & 31,500 \\
Euphorbia sp. & "leche leche" & 2,500 \\
\hline Total & & 68,000 \\
\hline
\end{tabular}

Para el caso de la "grama china" se determinó un promedio de 3.4 plantas $/ \mathrm{m}^{2}$ siendo la especie de mayor distribución en el campo de cítricos. Le sigue en abundancia el "yuyo" con un promedio de 3.15 plantas/ $\mathrm{m}^{2}$ lo que representa 31,500 plantas/ha. En tercer lugar se registró a "leche leche" con un promedio de 0.25 plantas/ $\mathrm{m}^{2}$ y 2,500 plantas/ha. 
En el cultivo de cítricos se recuperaron los siguientes insectos, clasificados por órdenes, familias, especies y status (plaga, benéfico o sin importancia económica).

Tabla 8. Ordenes de insectos recuperados por cada maleza en el cultivo de cítricos.

\begin{tabular}{ccc}
\hline $\begin{array}{c}\text { Nombre científico de } \\
\text { la maleza }\end{array}$ & Orden & $\begin{array}{c}\text { Población estimada } \\
\text { de insectos/ha }\end{array}$ \\
\hline Amaranthus sp. & Lepidoptera & 42,000 \\
& Diptera & 31,500 \\
Euphorbia sp. & Hemiptera & 21,000 \\
& Hemiptera & 32,500 \\
& Diptera & 1,667 \\
Sorghum halepense & Lepidoptera & 833 \\
Total & Diptera & 11,333 \\
\hline
\end{tabular}

Tabla 9. Familias de insectos recuperados por cada maleza en el cultivo de cítricos.

\begin{tabular}{|c|c|c|c|}
\hline $\begin{array}{c}\text { Nombre } \\
\text { científico de la } \\
\text { maleza }\end{array}$ & \multicolumn{2}{|c|}{ Familia } & $\begin{array}{c}\text { Estimado } \\
\text { por ha }\end{array}$ \\
\hline \multirow{4}{*}{ Amaranthus sp. } & \multicolumn{2}{|c|}{ Pyralidae } & 31,500 \\
\hline & Blastobasidae & 10,500 & \\
\hline & Agromyzidae & 31,500 & \\
\hline & Lygaeidae & 21,000 & \\
\hline \multicolumn{3}{|c|}{ Sub-Total } & 94,500 \\
\hline \multirow{3}{*}{ Euphorbia sp. } & \multicolumn{2}{|c|}{ Rhopalidae } & 32,500 \\
\hline & Syrphidae & 1,667 & \\
\hline & Tortricidae & 833 & \\
\hline \multicolumn{3}{|c|}{ Sub-Total } & 35,000 \\
\hline $\begin{array}{l}\text { Sorghum } \\
\text { halepense }\end{array}$ & \multicolumn{2}{|c|}{ Syrphidae } & 11,333 \\
\hline Total & & & 140,833 \\
\hline
\end{tabular}

Tabla 10. Especies de insectos identificados en cada maleza del cultivo de cítricos.

\begin{tabular}{|c|c|c|}
\hline $\begin{array}{c}\text { Nombre científico de } \\
\text { la maleza }\end{array}$ & Género y especie & $\begin{array}{l}\text { Estimado } \\
\text { por ha }\end{array}$ \\
\hline \multirow[t]{5}{*}{ Amaranthus sp. } & $\begin{array}{l}\text { Herpetogramma } \\
\text { bipunctalis }\end{array}$ & 21,000 \\
\hline & Spoladea recurvalis & 10,500 \\
\hline & Liorrhyssus sp. & 10,500 \\
\hline & Melanagromyza sp. & 31,500 \\
\hline & Nysius sp. & 21,000 \\
\hline \multicolumn{2}{|c|}{ Sub-Total } & 94,500 \\
\hline \multirow[t]{3}{*}{ Euphorbia sp. } & Liorrhyssus sp. & 32,500 \\
\hline & Mesograpta sp. & 1,667 \\
\hline & $\begin{array}{c}\text { Argyrotaenia } \\
\text { sphaleropa }\end{array}$ & 833 \\
\hline \multicolumn{2}{|c|}{ Sub-Total } & 35,000 \\
\hline Sorghum halepense & Syrphus sp. & 11,333 \\
\hline Total & & 140,833 \\
\hline
\end{tabular}

Según la Tabla 9, en el cultivo de cítricos, el "yuyo" alberga la mayor cantidad de insectos, seguido de la maleza "leche leche" y en menor escala en la "grama china".

En "yuyo" se recuperaron de 3.0 insectos por planta, los que al estimarse por hectárea, nos da una población desde 94,500. De igual manera, en "leche leche", se recuperaron en promedio 14 insectos por planta que proyecta una población hasta de 35,000 insectos/ha. En "grama china" se recuperó 1.133 insectos por planta, lo que al estimarse por hectárea nos da una población de 11,333 insectos/ha. La mayor cantidad de insectos recuperados en "yuyo" pertenecen al orden Lepidoptera, seguida del orden Diptera y, en menor proporción se recuperó insectos pertenecientes al orden Hymenoptera.

En "leche leche" se observa lo contrario debido a que las mayores poblaciones encontradas pertenecen al orden Hemiptera y mínimas poblaciones del orden Diptera y Hemiptera. En cuanto a las familias, en "yuyo" las mayores poblaciones pertenecen a las familias Pyralidae, Agromyzidae y Lygaeidae, seguidas de la familia Blastobasidae. En "leche leche" la mayor población pertenece a la familia Rhopalidae y con mínimas poblaciones de las familias Syrphidae y Tortricidae y en la "grama china" la población de insectos son de la familia Syrphidae, según se observa en la Tabla 8.

Tabla 11. Status de insectos recuperados, población de insectos estimada por hectárea y porcentaje de insectos por maleza, en el cultivo de cítricos.

\begin{tabular}{|c|c|c|c|}
\hline $\begin{array}{c}\text { Nombre científico } \\
\text { de la maleza }\end{array}$ & $\begin{array}{l}\text { Status del } \\
\text { insecto }\end{array}$ & $\begin{array}{c}\text { Estimado por } \\
\text { ha }\end{array}$ & $\begin{array}{l}\% \text { por } \\
\text { maleza }\end{array}$ \\
\hline \multirow[t]{3}{*}{ Amaranthus sp. } & plaga $(\mathrm{m})$ & 31,500 & 33.3 \\
\hline & plaga & 31,500 & 33.3 \\
\hline & sin import. conó. & 31,500 & 33.3 \\
\hline Sub-Total & & \multicolumn{2}{|l|}{94,500} \\
\hline \multirow[t]{3}{*}{ Euphorbia sp. } & \multirow{2}{*}{$\begin{array}{l}\text { sin import. } \\
\text { econó. } \\
\text { predator }\end{array}$} & 32,500 & 93 \\
\hline & & 1,667 & 5 \\
\hline & plaga & 833 & 2 \\
\hline Sub-Total & & \multicolumn{2}{|l|}{35,000} \\
\hline Sorghum halepense & predator & 11,333 & 100 \\
\hline Total & & 140,833 & \\
\hline
\end{tabular}

* Plaga (m): Plaga de malezas.

Tabla 12. Resumen del satus de insectos recuperados y población estimada por hectárea en el cultivo de cítricos.

\begin{tabular}{cccc}
\hline $\begin{array}{c}\text { Nombre del } \\
\text { cultivo }\end{array}$ & $\begin{array}{c}\text { Estatus del } \\
\text { insecto }\end{array}$ & $\begin{array}{l}\text { Estimado } \\
\text { por ha }\end{array}$ & $\begin{array}{c}\text { \% por } \\
\text { maleza }\end{array}$ \\
\hline & plaga $(\mathrm{m})^{*}$ & 31,500 & 22.23 \\
Citricos & plaga & 32,333 & 22.96 \\
& sin import. econ. & 64,000 & 46.44 \\
& predator & 13,000 & 9.24 \\
\hline Total & & 140,833 & 100 \\
\hline
\end{tabular}

* Plaga (m): Plaga de malezas.

En cuanto a las especies recuperadas en "yuyo"; las mayores poblaciones pertenecen a Melanagromyza sp., seguidas de Herpetograma bipunctalis y Nysius sp., y en 
menor escala Spoladea recurvalis y ninfas de Liorrhyssus sp. En la maleza "leche leche" las mayores poblaciones recuperadas pertenecen al género Liorrhyssus $\mathrm{sp}$. Le siguen con mínimas poblaciones Mesograpta sp. y Argyrotaenia sphaleropa. En la maleza Sorghum halepense, se determinó Syrphus sp., según la Tabla 10.

Tomando en cuenta el status de los insectos recuperados del cuadro 11, tenemos que en "yuyo" un 33\% de insectos representan a plagas de malezas, 33\% representan plagas de cultivos y $33 \%$ a insectos sin importancia económica. En "leche leche" el 93\% representa insectos sin importancia económica, 5\% representan a insectos benéficos y $2 \%$ representan a plagas de cultivos.

En total, en las malezas evaluadas en el cultivo de cítricos, se recuperaron 52 especímenes de insectos, representando un estimado de población por hectárea de 140,833 individuos, de los cuales el $46.44 \%$ no son de importancia económica, $22.96 \%$ son considerados plagas de cultivos, $22.23 \%$ representan a plagas de malezas y $9.24 \%$ son insectos benéficos, según la Tabla 12.

\section{Cultivo de lúcumo}

De las evaluaciones realizadas en campo y gabinete para el cultivo de lúcumo se determinaron las siguientes poblaciones de malezas de la Tabla 13.

Tabla 13. Proyección estimada de población de malezas predominantes en el cultivo de lúcumo, por hectárea.

\begin{tabular}{ccc}
\hline Nombre científico Nombre común & $\begin{array}{c}\text { Población } \\
\text { estimada } \\
\text { de plantas/ha }\end{array}$ \\
\hline $\begin{array}{c}\text { Sorghum } \\
\text { halepense }\end{array}$ & "grama china" & 75,000 \\
Bidens pilosa & "amor seco" & 62,500 \\
Amaranthus sp. & "yuyo" & 26,875 \\
\hline Total & & 164,375 \\
\hline
\end{tabular}

Para el caso de la "grama china" se determinó un promedio de 7.5 plantas $/ \mathrm{m}^{2}$ lo que hace un total de 75,000 plantas/ ha siendo la especie de mayor distribución en el campo de lúcumo evaluado. Le sigue en abundancia el "amor seco" con un promedio de 6.25 plantas $/ \mathrm{m}^{2}$ lo que representa 62,500 plantas/ha. En tercer lugar se determinó al "yuyo" con un promedio de 2.68 plantas $/ \mathrm{m}^{2}$ y 26,875 plantas/ha. Se recuperaron los siguientes insectos, agrupados por órdenes, familias, especies y status (plaga, benéfico o sin importancia económica), según las Tablas 14, 15, 16 y 17.
Tabla 14. Ordenes de insectos recuperados en el cultivo de lúcumo por cada maleza.

\begin{tabular}{lcc}
\hline $\begin{array}{c}\text { Nombre científico } \\
\text { de la maleza }\end{array}$ & Orden & $\begin{array}{c}\text { Población estimada de } \\
\text { insectos por ha }\end{array}$ \\
\hline Amaranthus sp. & Lepidoptera & 152,292 \\
Bidens pilosa & Diptera & 312,500 \\
& Coleoptera & 20,833 \\
Sorghum halepense & Hemiptera & 83,333 \\
\multicolumn{1}{c}{ Total } & & 0 \\
\hline
\end{tabular}

Tabla 15. Familias de insectos recuperados por cada maleza en el cultivo de lúcumo.

\begin{tabular}{|c|c|c|}
\hline $\begin{array}{c}\text { Nombre científico de la } \\
\text { maleza }\end{array}$ & Familia & Estimado por ha \\
\hline Amaranthus sp. & Pyralidae & 152,292 \\
\hline Subtotal & & 152,292 \\
\hline Bidens pilosa & $\begin{array}{l}\text { Agromyzidae } \\
\text { Tephritidae } \\
\text { Coccinelidae } \\
\text { Rhopalidae } \\
\end{array}$ & $\begin{array}{c}83,333 \\
229,167 \\
20,833 \\
83,333 \\
\end{array}$ \\
\hline $\begin{array}{r}\text { Subtotal } \\
\end{array}$ & & 416,666 \\
\hline Sorghum halepense & -- & 0 \\
\hline Total & & 568,958 \\
\hline
\end{tabular}

Tabla 16. Especies de insectos identificados en malezas del cultivo de lúcumo.

\begin{tabular}{ccc}
\hline $\begin{array}{c}\text { Nombre científico } \\
\text { de la maleza }\end{array}$ & Género y especie & $\begin{array}{c}\text { Estimado } \\
\text { por ha }\end{array}$ \\
\hline Amaranthus sp. & Spoladea recurvalis & 53,750 \\
& Herpetogramma & 98,542 \\
bipunctalis & 152,292 \\
\hline Subtotal & 83,333 \\
\hline Bidens pilosa & Melanagromyza sp & 229,167 \\
& Dioxyna sp. & 20,833 \\
& Psyllobora sp. & 83,333 \\
\hline \multicolumn{3}{c}{ Subtotal } \\
\hline Sorghum halepense & 416,666 \\
\hline Total & -- & 0 \\
\hline
\end{tabular}

Tabla 17. Status de insectos recuperados, población de insectos estimada por hectárea y porcentaje de insectos por maleza, en el cultivo de lúcumo.

\begin{tabular}{|c|c|c|c|}
\hline $\begin{array}{c}\text { Nombre } \\
\text { científico de la } \\
\text { maleza }\end{array}$ & $\begin{array}{l}\text { Estatus del } \\
\text { insecto }\end{array}$ & $\begin{array}{l}\text { Estimado } \\
\text { por ha }\end{array}$ & $\begin{array}{l}\% \text { por } \\
\text { maleza }\end{array}$ \\
\hline Amaranthus sp. & plaga $(\mathrm{m})^{*}$ & 152,292 & 100 \\
\hline \multirow[t]{3}{*}{ Bidens pilosa } & plaga & 83,333 & 20 \\
\hline & sin import. econ. & 312,500 & 75 \\
\hline & micófago & 20,833 & 5 \\
\hline \multicolumn{2}{|c|}{ Sub-Total } & 416,666 & 100 \\
\hline $\begin{array}{l}\text { Sor } r \text { g h u } m \\
\text { halepense }\end{array}$ & -- & 0 & 0 \\
\hline Total & & \multicolumn{2}{|c|}{568,958} \\
\hline
\end{tabular}

* Plaga (m): Plaga de malezas. 
Tabla 18. Resumen del status de insectos recuperados y población estimada por hectárea en el cultivo de lúcumo.

\begin{tabular}{cccc}
\hline $\begin{array}{c}\text { Nombre del } \\
\text { cultivo }\end{array}$ & $\begin{array}{c}\text { Estatus del } \\
\text { insecto }\end{array}$ & Estimado por ha & $\begin{array}{c}\text { \% por } \\
\text { maleza }\end{array}$ \\
\hline \multirow{4}{*}{ lúcumo } & plaga $(\mathrm{m})^{*}$ & 152,292 & 26.81 \\
& plaga & 83,333 & 14.65 \\
& sin import. & 312,500 & 54.92 \\
econ. & 20,833 & 3.66 \\
\hline & micófago & 568,958 & 100 \\
\hline
\end{tabular}

* Plaga (m): Plaga de malezas.

Se puede observar que, en el cultivo de lúcumo, la maleza "amor seco" alberga la mayor cantidad de insectos, seguida del "yuyo" con una cantidad ligeramente menor, en cambio no se recuperó ningún insecto de la "grama china". Se recuperaron 6.66 insectos por planta, los que al estimarse por hectárea, nos da una población de 416,666 insectos/ha. De igual manera, en "yuyo" se recuperaron 5.66 insectos por planta, los que al estimarse por hectárea, según la población de esta maleza, se registra una población de 152,292 insectos/ha.

En este caso se han recuperado insectos en las 3 plantas muestreadas tanto de "amor seco" como de "yuyo" lo que nos indica una distribución relativamente más uniforme de poblaciones de insectos en estas dos malezas en todo el campo.

El mayor número de insectos recuperados en "amor seco" son dípteros y en menor escala son hemípteros y coleópteros; en el "yuyo" todos son lepidópteros. Las mayores poblaciones encontradas en "amor seco" son de las familias Tephritidae, Agromizidae y Rhopalidae y en mínimas poblaciones Coccinellidae y entre las especies las mayores poblaciones son de Dioxyna sp. sin importancia económica, las poblaciones menores son de Melanagromyza sp. y Liorrhyssus sp. y mínimas poblaciones de Psyllobora sp. En "yuyo" la mayor población pertenece a Herpetograma bipunctalis, seguida de Spoladea recurvalis.

Tomando en cuenta el status de los insectos recuperados de la Tabla 17 y 18 tenemos que, en "amor seco" un 75\% corresponden a insectos sin importancia económica, un $20 \%$ de insectos representan a plagas de cultivos y $5 \%$ a insectos benéficos. En "yuyo" el 100\% representan a plagas de malezas.

En total, en las malezas evaluadas en el cultivo de lúcumo, se recuperaron 37 especímenes de insectos, representando un estimado de población por hectárea de 568,958 individuos, de los cuales el $54.92 \%$ no son de importancia económica, $26.81 \%$ son considerados plagas de malezas, $14.65 \%$ representan a plagas de cultivos y $3.66 \%$ son insectos benéficos.

Los resultados evidencian que los cultivos albergan una población de insectos que se encuentran en malezas en cantidades que son importantes considerar al momento de establecer una estrategia de control. En el caso del cultivo del maíz, existe una población de malezas de 234,000 malezas por hectárea y que pueden albergar cerca de 1'100,000 insectos que pueden ser plagas y no plagas o reservorios potenciales de enfermedades virales. En el caso del cultivo de cítricos se tiene que se puede tener por hectárea cerca de 68,000 malezas, que podrían albergar cerca de 140,833 insectos. En el caso del cultivo de lúcumo se observa que se tiene 164,375 malezas por hectárea que pueden albergar cerca de 568,958 insectos. Esta cuantificación, ayuda a comprender la forma en que los insectos pueden colonizar diferentes cultivos, primero asociándose con malezas, para posteriormente convertirse en problemas en los cultivos que se encuentran cercanos, tal como lo menciona National Academy Sciences (1990).

Las malezas constituyen un elemento biótico que influye en las diferentes interrelaciones dentro de un agroecosistema. Se confirma que las malezas predominantes para los diferentes cultivos varían notoriamente si el cultivo es anual o si es un frutal, a pesar de que la localización de los campos evaluados no diste más de 200 metros entre sí. Las diferentes malezas por cada cultivo dependen de la preparación de terreno, prácticas culturales, niveles tróficos hasta el nivel de vertebrados, tal como lo explica Marshall et al (2003), quien manifiesta que la flora de los cultivos puede cambiar en el tiempo, debido a los cambios en la profundidad de la preparación de terrenos o por la combinación en el uso de herbicidas, y añade que la reducción de una determinada especie de planta puede desencadenar reacciones asociados con insectos de otra taxa, esta situación afectaría la presencia de determinados tipos de insectos que afectaría a su vez la presencia de determinadas especies de aves que se alimentan de insectos.

Estas interrelaciones de cadenas tróficas, se van a dar, dependiendo de la naturaleza de las malezas y del cultivo en cuanto a su fenología o disponibilidad de alimento, tal como lo menciona, Villegas et al (2013), que encontró que la maleza Sylibium marianum (L.) que se encontraba en la periferia del cultivo de "alfalfa" (Medicago sativa L.) sirve como hospedero alternativo de Hippodamia convergens ya que se encontraba predatando pulgones en la maleza, y que su frecuencia depende de la distancia de la planta hospedera alternativa.

Otra evidencia del presente estudio es la existencia de poblaciones de himenópteros que podrían estar ejerciendo su labor parasítica en malezas y en cultivos principales como en el caso de maíz, en que se encontró un grupo de himenópteros de la familia Pteromalidae, cuya población expresada por hectárea es de 41,667 individuos por hectárea colectados en Datura stramonium. En los grupos parasíticos sólo las formas inmaduras subsisten a expensas del hospedante; los adultos requieren fuentes alimenticias alternas, frecuentemente polen y/o néctar de las flores conjuntamente con el rocío. Muchas veces las malezas son la única fuente de flores en el agroecosistema convirtiéndose esas plantas en un recurso de gran importancia para que los adultos de los parásitos 
puedan sobrevivir durante períodos críticos cuando los hospedantes son escasos (Syme, 1975). Así, los parásitos tienen más oportunidades de establecerse en áreas donde puedan encontrar una rica vegetación de plantas productoras de néctar y polen, que en aquellas áreas ausentes de flores silvestres, aspecto a considerar cuando se decide implantar programas de manejo integrado de plagas (Altieri, 1976, 1980, 1981) y (Altieri y Whitcomb, 1979).

Por otro lado, existen parasitoides que requieren la presencia de flores para lograr una fecundidad y longevidad normales. Muchos parasitoides adultos sobreviven en períodos críticos alimentándose de flores de malezas cuando escasean sus huéspedes (Driesche y Bellows, 1996). La proximidad de ciertas malezas en floración con campos cultivados ha resultados en un incremento del parasitismo de plagas en caña de azúcar (Leeper, 1974).

Asimismo, las malezas pueden desencadenar epizootias de enfermedades tanto fungosas como virales que pueden afectar a cultivos como las solanáceas. En nuestro estudio las maleza Datura stramonium, Amaranthus sp. y Sorghum halepense, son malezas que se les ha reportado como reservorio de enfermedades virales, especialmente en los cultivos de solanáceas y cucurbitáceas, tal como lo menciona Apablaza et al (2003), que menciona a estas plantas como Datura stramonium, Amaranthus spp., Raphanus sativus, Chenopodium album, Galega officinalis, Conium maculatum, Sonchus asper, Malva sp., Urtica urens, Bidens sp., Brassica campestris, Sorghum halepense y Solanum sp., reportándose en estas malezas cinco virus: El virus del mosaico de la alfalfa (AMV), el virus del mosaico del pepino (CMV), el virus del marchitamiento manchado del tomate (TSWV) virus "Y" de la papa (PVY), el virus del mosacio del tomate (ToMV) y el virus del mosaico de la sandía (WMV2). También reportó insectos que pueden transmitir algunos de estos virus como Myzus persicae y Thrips tabaci. En el caso de que los terrenos los quisieran rotar, especialmente el que viene del cultivo de maíz, para cultivos como solanáceas y cucurbitáceas, el resultado sería infestaciones muy adelantadas, ya que tenemos presencia de insectos de la familia Aphididae en una proyección por hectárea de 116,000 individuos con la presencia de las malezas Datura stramonium y Sorghum halepense.

Se observa que la mayor parte de los insectos pertenecen a la categoría de insectos sin importancia económica, seguido de los insectos plagas en cultivos, seguido de insectos que afectan a las malezas (por eso se les considera plaga en malezas) e insectos benéficos. Estas cifras nos hacen ver que la entomofauna está en cierto equilibrio y que sigue una dinámica poblacional que puede romperse al momento de hacer una medida de manejo como aplicaciones de herbicidas o manejo culturales cuando el cultivo se encuentra instalado que podría afectar al cultivo principal. Por lo que las medidas más radicales se podrían realizar siempre al inicio de campaña, cuando no existe cultivo, ya que que si lo hay las dinámicas poblacionales podrían afectar a los cultivos. Respecto a los insectos benéficos, es la que tiene menor presencia, probablemente por el tipo y momento del muestreo realizado que puede hacer variar los resultados. Esto coincide con lo mencionado por Altieri (1980), que menciona que todos los insectos, están en un equilibrio de homeóstasis y que la intervención del hombre, puede hacer que este equilibrio desaparezca.

Para luchar contra ellas, existe toda una metodología de trabajo que va desde los controles manuales, culturales, biológicos y químicos; pero que siempre se deben realizar en forma conjunta para hacerles frente de la mejor manera sin alterar el equilibrio biológico que debe existir en cualquier área agrícola (National Academy of Sciences 1990).

\section{Conclusión}

Las maleza predominante para los tres cultivos fue Sorghum halepense, seguida de Amaranthus sp., y para el caso de poblaciones de insectos este orden se invierte; sin embargo, en Cyperus rotundus no se registraron insectos; probablemente debido a la metodología de evaluación realizada, ya que se evaluaron insectos adultos emergidos de la colección realizada en campo.

Existe diferencias entre las especies de maleza en los tres cultivos, siendo Sorghum halepense la que está presente en los tres cultivos evaluados. Las malezas presentes en maíz, Datura stramonium y Cyperus rotundus, se les reporta como abundante en este cultivo, mientas que para el caso del cultivo de cítricos son el Amaranthus spp. y Euphorbia spp; y por último, para el cultivo de lúcumo, se reporta a Amaranthus spp. y Bidens pilosa.

Se identifica a la especie de maleza Amaranthus sp. como única planta hospedera de Herpetograma bipunctalis y Spoladea recurvalis, que son plagas de hortalizas. También se encontró que Euphorbia sp. es hospedante de Argyrotaenia sphaleropa, plaga importante en cítricos.

En el cultivo del maíz, se obtuvo 1'100,000 insectos estimados por hectárea, y de acuerdo a su estatus 614,333 son plagas de cultivos (55.84\%), 444,000 sin importancia económica $(40.36 \%)$ y 41,667 son insectos benéficos (3.79\%). En cítricos, se obtuvo 140,833 insectos estimados por hectárea, de los cuales 31,500 son plagas en malezas $(22.23 \%), 32,333$ son plagas en cultivos (22.96\%), 64,000 sin importancia económica (46.44\%) y 13,000 son insectos benéficos (9.24\%). En lúcumo, se obtuvo 568,958 insectos estimados por hectárea, de los cuales 152,292 son plagas en malezas $(26.81 \%), 83,333$ son plagas en cultivos (14.65\%), 312,500 sin importancia económica $(54.92 \%)$, y 20,833 son insectos benéficos $(3.66 \%)$. 


\section{Literatura citada}

Altieri, S, Ma. 1976. Regulación ecológica de plagas en agroecosistemas tropicales. Un ejemplo: mono y policultivos de maíz y frijol, diversificados con malezas. Tesis magister scientiae (un-ica). Universidad nacional de colombia. Bogotá, colombia. 177 p.

Altieri ,S. Ma. and Whitcomb, Wh. 1979. The potential use of weeds in the manipulation of beneficial insects. Hort. Science 14(1): 12-18.

Altieri, S. Ma. 1997. Agroecología. Bases científicas para una agricultura sustentable. Editorial clades, 1997. 249 pp.

Altieri, S. Ma. 1980. The need for an agroecological approach to pest management. Env. Management 4(6): 467-468.

Altieri, S. Ma. 1981. Weeds may augment bilogical control of insects. Calif. Agr. May - june. 35(5-6): 22-24.

Apablaza, G.; Apablaza, J.; Reyes, G. y Moya, E. 2003. Determinación de virosis en insectos vectores en malezas aledañas en cultivos hortícolas. Ciencia e investigación agraria. Vol $30 n^{\circ} 3,2003$, pags 175-186.

Cerna, L. 1994. Manejo mejorado de malezas. Editorial libertad eirl. Perú 320 pp.

Cisneros, f. 1995. Control de plagas agrícolas. 313 pp.

Driesche, R. and Bellows, T. 1996. Biological control. Chapman \& hall. 1996. 538 pp.

Landis, da; wratten, sd and gurr, gm. 2000. Habitat management to conserve natural enemiges of arthropod pest in agriculture. Annual review of entomology 45:175201.

Leeper, Jr. 1974. Adilt feeding behavior of lixophaga sphenophori, a tachinid parasite of the new guinea sugarcane weevil. Proc. Hawaiian ent. Soc. 21: 403-412.

Marshall, E,; Brown, V,; Boatman, N,; Lutmans, P.; Squire, G. and Ward, L. 2003. The role of weeds in supporting biological diversity within crop fields. European weed research society 2003 43, 77-89.

Menash, R. and Sequeira, R. 2004. Habitat manipulation for insect pest management in cotton cropping system. In gurr, gs; wratten, s and altieri, m (eds). Ecological engineering for pest management: advances in habitat manipulation for arthropods csiro publishing. Collingwood, australia $225 \mathrm{pp}$.

National Academy of Sciences. 1990. Editorial limusa. Vol 2. México. 574 pp.

Syme, p. 1975. The effects of flowers on the longevity and fecundity of two native parasites of the european pine shoot moth in ontario. Enviromental entomology. Volume 4, number 2, april 1975, pp 337-346(10).

Villegas, C.; Verdufgo, J.; Grez, A.; Tapia, J. and Lavandero, B. 2013. Movement between crops and weeds: temporal refuges for aphidophagous insects in central chile. Ciencia e investigación agraria 40 (2): 317 326. 